\title{
versants
}

\section{La ética como estética del presente (De la formación ideológica de Miguel Hernández)}

\author{
Jorge URRUTIA \\ Universidad Carlos III de Madrid \\ ORCID: 00oo-0ooI-7796-755X
}

\begin{abstract}
El artículo desea mostrar la evolución estética de Miguel Hernández desde la figura del poeta-pastor de sus inicios hasta el poeta neopopular del Cancionero y Romancero de ausencias, a través de su trayectoria ideológica. Se resalta la importancia de un poema habitualmente considerado menor, para su autodescubrimiento como poeta proletario y la fijación de una poética ética.

Keywords: Miguel Hernández, neopopularismo, poesía proletaria, poética.
\end{abstract}

El 26 de febrero de I828, abriendo el periódico El Duende Satírico del Día, Mariano José de Larra publicó su primer artículo, «El café». Empezaba: «No sé en qué consiste que soy naturalmente curioso; es un deseo de saberlo todo que nació conmigo, que siento bullir en todas mis venas». Esa curiosidad continuó hasta su último artículo, «Fígaro a los redactores de El Mundo», publicado el 29 de enero de i837. Nueve años en los que cuestionó la conciencia y la imagen social del país.

Miguel Hernández publica su primer poema, «Pastoril», el I3 de enero de I930 en El pueblo, de Orihuela. Fecha en septiembre de 1939, desde la Cárcel de Torrijos (convento que existe en la calle madrileña de Conde de Peñalver), el que probablemente sería el último, «Ascensión de la escoba». Nueve años en los que recorre casi toda la historia de la modernidad poética española, para llegar a entender la conciencia social de España.

No puede menos que llamar a la puerta de nuestra atención esa coincidencia vital en solo nueve años de escritura. Dos autores que marcan la literatura española desarrollan su obra en un lapso brevísimo con un siglo exacto de intervalo. La casualidad otorga sentidos inesperados. Pareciera, además, que ambos jóvenes sintiesen la inevitabilidad de su destino y decidieran vivir a toda prisa, tragando el aire más que respirando, y eso, en literatura, implica intuición más que reflexión.

Miguel Hernández fue un poeta intuitivo y, gracias a esa capacidad de percepción, fue prescindiendo sistemáticamente de modos de escritura y adoptando otros. Así se explica que el I2 de diciembre de I93I escriba desde Madrid a Ramón Sijé, después de haberse entrevistado con Giménez Caballero: «Yo, 
como siempre, nunca satisfecho de nada de lo que hago. Siento en mí un ansia de superación».

Según el diccionario, el ansia es una congoja que causa en el cuerpo una agitación violenta.

-El ansia mueve a la acción inmediata: «He roto casi todos los [poemas] que leíste». Probablemente influyó aquí la conversación con Giménez Caballero.

-También incita el ansia al entusiasmo y al optimismo: «Me ha prometido [Giménez Caballero] sacarme a flote».

-Del mismo modo el ansia empuja a la impaciencia y, tras esta, a la posible desesperación: «¿Cuándo daré con mi forma? Es mucha mi manía por hallarla. No lo hago por eso [por manía]».

-Así mismo, el ansia de mejorar puede conducir a la autocrítica: «Sabes que he compuesto versos siguiendo... a Miró y de los demás poetas... radioscopia».

-Por último, puede conducir a echar sobre otro la responsabilidad o la crítica: «Procuro que lo que diga sea mío nada más. Algún día será que quede libre de extrañas influencias. Ya sé que me las achacas» (Hernández I986: 3I-32).

Sorprende esta última afirmación cuando el 2 de febrero de aquel mismo año I93I había publicado «A todos los oriolanos. Carta completamente abierta», poema donde confiesa que en sus escritos «hay imitaciones / harto serviles y bajas, / reminiscencias y plagios / y hasta estrofitas copiadas» (Hernández 20I7: 7IO). Sé bien que el poema era una suerte de captatio benevolentiae que buscaba la comprensión de los lectores de su pueblo. Afirma que se cree poeta, «digno de contender / con Homero, con Petrarca, / con Virgilio, con Boscán, / con Dante y toda la escuadra», pero advierte: «...a los que yo no conozco / más que de oídas... y gracias». Porque se declara aún poco formado: «...vengo publicando / con muchas y gruesas faltas / de prosodia y de sintaxis, / de ritmo y de consonancia».

Hoy, ese discurso no parece sincero y sí comercial. De hecho, Miguel se muestra siempre preocupado por el triunfo dinerario: «Mi única ilusión sería... ganar mucho, mucho dinero... el... para volver a Oleza y a la orilla... del Segura estarme cantando hasta morir!» [sic] (Hernández I986: 3I). Insistencia que manifiesta en su correspondencia. Antonio Machado, a través de Juan de Mairena, se reiría de la captatio benevolentiae, esa búsqueda del acogimiento por parte del lector, disminuyendo la propia capacidad para aumentar sus méritos (Machado I936: I5).

Por el ansia continua y la inseguridad que le producía, se comprende la cantidad de borradores por los que pasan sus poemas. Sin embargo, tuvo fama de repentizador, de ser un poeta de escritura fácil, probablemente porque se sabía sus poemas de memoria. Un ejemplo interesante de esa fama 
improvisadora es el poema «No salieron jamás...», perteneciente al Cancionero y Romancero de ausencias. Antonio Buero Vallejo, en un famoso artículo, refirió que, coincidiendo Hernández y él en una prisión al terminar la guerra civil, improvisó en la celda un poema, que tituló «Vals de los enamorados y unidos para siempre», para que un compañero se lo regalara a su mujer (Buero Vallejo I960). Sin embargo, contamos con manuscritos anteriores y, aunque Antonio Buero pensaba que lo daba a conocer, ya se había impreso antes de su artículo (Hernández 1952: 196). Probablemente lo único que el poeta improvisó en la celda fuera el título.

En el colegio, el mismo al que había asistido Gabriel Miró, los jesuitas habían despertado su interés por la poesía, en el tono católico y conservador acorde con el ambiente. Al paso temprano de Hernández por los grupos derechistas o socialistas, no debería dársele otro valor que el de integrarse en una asociación que llevaba a cabo actividades culturales y sociales, donde estará su pronto amigo Ramón Sijé. Las lecturas que hace son las posibles en aquellas circunstancias: poesía clásica, sin duda, aunque con restricciones, alguna incursión por el Siglo de Oro (durante su primer viaje a Madrid dirá que sus autores preferidos eran Góngora, Gabriel Miró y García Lorca) y la obra de los poetas realistas de la segunda mitad del siglo xix, con algún añadido romántico. He dicho en varias ocasiones que en sus primerísimos poemas se aprecia que imita a los poetas que lee: Zorrilla, Espronceda, Campoamor, Federico Balart, Darío, Salvador Rueda, Medina, Gabriel y Galán... (Hernández 20I7: 639). Las influencias siguientes las han estudiado José María Balcells en «La prehistoria poética de Miguel Hernández» (I99I y 2009) y Mercedes López-Baralt en «Tradición y vanguardia: las fuentes múltiples de Miguel Hernández» (20IO).

Igual que hiciera con los poetas decimonónicos, leerá intensamente a los modernos y se deja empapar por temas, modos e, incluso, expresiones. Rafael Alberti, en un poema famoso por ser de los primeros que en España tratan un asunto del deporte, mitifica al portero del Fútbol Club Barcelona, el húngaro Platko, quien se abriera la cabeza al golpearse durante el juego contra un poste: «Nadie se olvida, Platko, / no, nadie, nadie nadie, / oso rubio de Hungría / [...] Ni el mar, ni el viento, Platko, / rubio Platko de sangre, / guardameta en el polvo, / pararrayos». Miguel Hernández, aficionado al fútbol, toma la idea para glosar un episodio similar aunque más trágico, pues Lolo, guardameta del equipo de Orihuela, murió durante un partido al golpearse en la cabeza con la portería: «Fue un plongeon mortal. Con ¡cuánto! tino / y efecto, tu cabeza / dio al poste. Como un sexo femenino, / abrió la ligereza / del golpe una granada de tristeza». Que Hernández siguió el modelo literario se demuestra porque no presenció el hecho, sino que lo leyó en la prensa y vio una fotografía: «Te sorprendió el fotógrafo el momento / 
más bello de tu historia / deportiva, tumbándote en el viento / para evitar victoria, / y un ventalle de palmas te aireó la gloria».

Gerardo Diego incluye la expresión «azucenas en camisa» en el libro Poemas adrede. Empieza un poema: «Venid a oír de rosas y azucenas / la alborotada esbelta risa / Venid a ver las rosas sin cadenas / las azucenas en camisa». No creo que pueda ofrecer muchas dudas que Hernández tiene el recuerdo de esa imagen cuando escribe, en el poema que titula «El adolescente»: «¡Cuánto lilio en calzoncillos / se queda sobre los céspedes!». Lirios en calzoncillos frente a azucenas en camisa. Hay una diferencia en la elegancia del léxico. Miguel siempre tuvo algunas caídas en un gusto no precisamente exquisito, que molestaba sobremanera a García Lorca. Perito en lunas abusa, de hecho, de lo escatológico.

En el mimetismo hernandiano encontramos el deseo de separarse del mundo rural, de conocer a gentes distintas o, al menos, entrar en otro tipo de conversaciones del que hubiera tenido de haber permanecido ligado a la huerta. Miguel Hernández, tras un leve cambio de orientación en su vida, pasa a integrarse entre quienes manejaban habitualmente la lectura y la escritura en la vida diaria y no de modo tangencial. Una foto del poeta con chaqueta y corbata hacia I93I simboliza muy bien su búsqueda de una situación vital y cultural diferente. Eso es lo que le permitirá conocer a José Marín Gutiérrez, quien firmaría como Ramón Sijé, tres años menor que él, pero que se va a convertir en su primer maestro de estética literaria, después de sus inquietudes estilísticas tomadas de Gabriel Miró. Miguel encontró en aquel estudiante universitario en Murcia un guía para internarse por una poesía coetánea, a la que no había tenido acceso aún. Deja, por lo tanto, de pensar en los lectores pueblerinos para aspirar a ser leído por un público intelectual.

Dije que el primitivismo un poco brutal que había en Miguel Hernández es lo que debía incomodar a García Lorca. También a Ramón Gaya y a otros. Es conocida la anécdota según la cual Lorca telefoneó a Vicente Aleixandre para anunciarle que pensaba ir a visitarlo; al enterarse de que estaba allí el oriolano, dijo inmediatamente: «Entonces mejor no voy». La masculinidad desbordante de Miguel (y no hay en esta palabra ninguna intención oculta) era rechazada por Lorca, y Perito en lunas, su primer libro, tiene demasiados falos y semen. El origen poco refinado de Hernández, que para los amigos superaban su simpatía, su naturalidad y su entusiasmo, marcó sin duda en exceso los inicios del poeta. Leopoldo de Luis ha insistido, sin embargo, en varias ocasiones sobre la excepción que significa ver, en el medio campesino español de los años veinte, cómo un hijo de familia modesta asistía al colegio hasta los catorce años. Ello no implica que en I933 poseyera ya la formación de un intelectual burgués, aunque las nuevas amistades murcianas lo habían puesto por mejor camino. La exquisita educación de García 
Lorca, quien se sintió pronto asediado por las peticiones de Miguel, no llega a ocultar su molestia. En la carta que le escribiera en abril de ese año, viene a decirle que Perito en lunas es un libro primerizo, aunque prometedor, que la crítica siempre presta poca atención a los primeros libros, por lo que no debe obsesionarse, y que carece de motivos para sentirse incomprendido. Ahora bien, encuentra en el volumen "cosas brutales», debido sin duda a un entusiasmo de «corral», y lo ve repleto de "pasión de hombre», lo que no implica presumir de «cojones» (García Lorca 1927: 756-757):

\begin{abstract}
Quizá no sea desacertado recordar que la gran mayoría de los poetas que integraron la generación del 27 eran pequeños burgueses. Universitarios los más, o no tenían que trabajar (García Lorca), u ocuparon puestos de profesor (Salinas, Guillén, Alonso, Diego), o bien trabajaron por gusto (Altolaguirre, Prados, en su imprenta). La condición económica de la mayoría de estos escritores les permitía mantenerse alejados de la vida diaria. Esta distancia hacía posible a su vez el apartamiento casi absoluto de toda preocupación ética, política o moral en la poesía (Geist 1980: I04-I05).
\end{abstract}

Tal vez no sea del todo exacta esta opinión de Anthony Leo Geist, pero si añadimos los nombres que, sin salirnos de la nómina que compone la generación del 27 para él y que no cita en este párrafo (Rafael Alberti, hijo de familia burguesa; Vicente Aleixandre, que vive de rentas familiares; José Bergamín, hijo de ministro; Luis Cernuda, hijo de ingeniero militar y también profesor), comprendemos que hay una clara distancia social entre todos ellos y Miguel Hernández.

El 2 de febrero de I93I había publicado Hernández en El Pueblo, de Orihuela, un poema donde se presentaba como poeta-pastor: «A vosotros me dirijo / desde esta carta arrimada, / que escribo teniendo por / mesa el lomo de una cabra, / en la milagrosa huerta / mientras cuido la manada de habas» (Hernández 20I7: 707-7II). Hernández solo busca ser un campesino que hace versos sobre experiencias que todos experimentan. Repasando los primeros escritos, aparecen títulos que remiten a la cotidianidad de un pueblo. Incluso en 1930 escribe algún poema en el dialecto de la huerta, el murciano, conocido como panocho, que seguía la trocha abierta, aunque de escaso recorrido, por el poeta regionalista Vicente Medina.

En noviembre de 193I, Miguel Hernández envía a Juan Ramón Jiménez una carta en la que construía el personaje con que buscaba entrar en el mundo literario madrileño, compuesto de tres características (Hernández 1986: 27-28):

a) Es un pastor: «Soy pastor de cabras desde mi niñez. Y estoy contento de serlo, porque habiendo nacido en casa pobre, pudo mi padre darme otro oficio y me dio este que fue de dioses paganos y héroes bíblicos». 
b) Es pobre: «Odio la pobreza en que he nacido [...]. Particularmente por ser causa del estado inculto en que me hallo, que no me deja expresarme bien ni claro, ni decir las muchas cosas que pienso».

c) Es poeta: «Tengo un millar de versos compuestos, sin publicar».

Insistió en ello en varias ocasiones, pues el i9 de diciembre le escribe (Hernández 1983: 3I) a Ernesto Giménez Caballero en términos similares; se refiere a «La vida que he hecho hasta hace unos días desde mi niñez, yendo con cabras y ovejas», o a «Las pocas pesetas que traje conmigo a Madrid se agotan. Mis padres son pobres...». Hernández ya había visitado al director de La Gaceta Literaria ("Comprendiendo que no puede usted desperdiciar un átomo de tiempo, no he querido visitarle otra vez») y las referencias de prensa que le dedican comentan su vida de pastor. Como poeta-pastor había llegado a Madrid a finales de 193I. A los pocos días se entrevistó con Ernesto Giménez Caballero, que no lo tomó muy en serio ni, desde luego, lo ayudó, al menos con la rapidez que Hernández demandaba. Fue a visitarlo el io de diciembre de I931 y nueve días más tarde ya le escribía preguntándole «qué hay de lo mío» (Hernández 1986: 3I-32). Giménez Caballero lo ridiculiza el primero de enero en la revista:

Queridos camaradas literarios: ¿No tenéis algunas ovejas que guardar? Gobierno de intelectuales: ¿No tenéis algún intelectual que esté como una cabra para que lo pastoree este muchacho? ¿Quién ayuda al nuevo pastor poeta? ¿Qué ganado se le confía? ¡A ver! ¡Entre todos! ¡Un enchufe para este campesino! ¡Un destinejo para este montaraz! [...] ¡Hacedle aunque sea ferroviario! ¡A ver, a ver! ¡Vosotros, los literatos influyentes y mangoneadores! ¡Un premiecillo nacional para este pastor! ¡Para este poeta parado! (Santonja I984).

Miguel no resultaba, ni siquiera, una novedad, pues un personaje habitual de las reuniones literarias, desde que José Ortega Munilla lo dio a conocer en 1923 en un acto en el Ateneo de Madrid, era Julián Sánchez Prieto, que se firmaba «El pastor poeta». Hijo también de pastor, Sánchez Prieto publicaba poesía y teatro.

Erving Goffman estudió las estrategias de interacción social y la creación individual de «personajes» adecuados a cada situación (Goffman 200I). En el caso de Hernández, el fracaso de la estrategia de presentación fue evidente. Tuvo que regresar a Orihuela arruinado, enfermo y medio muerto de hambre. Debe enterrar su imagen de pastor. La estancia capitalina fue, sin embargo, importante porque leyó mucho y llevó a cabo un aprendizaje fundamental: la vida del poeta no debe entrar en el poema como biografía, sino como experiencia. Y la experiencia no es solamente vital, sino también lectora. 
El 2 de octubre de 1932 conoce a Antonio Oliver Belmás, quien acaba de abrir, con Tiempo cenital, la colección «Sudeste», ligada al diario La Verdad, de Murcia. Oliver sirve de intermediario para la publicación del primer libro de Hernández, Poliedros, por cuatrocientas veinticinco pesetas. El poeta reclama respuesta inmediata a sus misivas, incorporando y sustituyendo poemas hasta el último momento. Tiene muy claro que se paga el libro (como más tarde con El rayo que no cesa), pues en carta del 6 de diciembre le dice al editor: «...es que quiero, ya que voy a publicarme, hacerlo con lo mejor mío» (Hernández I983: 47). Todavía el 6 de diciembre, pide que se sustituyan nueve poemas. Luego, una vez aparecido el libro el 20 de enero de 1933 , insiste, en su correspondencia a los amigos y conocidos, en que le ayuden a venderlo para poder resarcir sus deudas.

Más allá de los aspectos económicos, de su correspondencia deducimos que Miguel Hernández está muy preocupado por el libro, por el contenido y por el título. El 3 de noviembre de I932, cuando acaba de enviar el original, le pide a Raimundo de los Reyes, el poeta editor, que sustituya el título del manuscrito por Perito en lunas. Una vez impreso, obliga a encartar una fe de erratas, generalmente de signos de puntuación o fácilmente subsanables en la lectura.

Conservamos una cuartilla con un primer índice del libro, el título inicial y un dibujo alusivo. ¿Cómo se pasa de Poliedros a Perito en lunas? Expliqué en otras ocasiones el título del primer libro hernandiano (Urrutia 2004 y 20I0). No es cuestión de que me repita aquí, pero sí conviene volver brevemente porque con ello se entiende bien el juego teórico y vital que mueve el poeta.

«Perito» significa conocedor, especialista. Sijé, en el delantal que pone al libro, termina con una referencia a la pericia del poeta: «Miguel Hernández [...] ha resuelto, técnicamente, su agónico problema». Ha resuelto técnicamente... Hernández es, pues, un perito que domina una técnica. ¿Cuál es el agónico problema? La «conversión del "sujeto" en "objeto" poético», lo que se corresponde, según aprendió en Madrid, al abandono de la biografía por la experiencia. Sijé distingue tres momentos cristalinos o lunas en la evolución del poeta: el del «poema terruñero, provincial, querencioso de pastorería de sueños»; el poema literario, «cuando la poesía es un grito estridente» porque no sabe el poeta si la poesía depende de la poética o al contrario; y, por último, el poema producto de una «acción transformante y unificante de una realidad misteriosa». Para el guía estético que es Sijé, Hernández ha hecho ya ese recorrido hasta el poema perfecto, que tiende a una figura geométrica, el cubo.

¿Cómo puede simbolizarse esa sublimación de la biografía hasta la experiencia compartible? En un artículo sobre Rafael Alberti, publicado algo más tarde en la revista El gallo crisis, que dirigía el propio Sijé, leemos: 
«Si la poesía puede cerrarse sobre sí misma - si puede concebirse una poesía pura- es por la conversión de la corriente en cristal, de la poesía en objeto». Escribir el poema será cristalizar: «No hay objeto poético donde no hay un alma capaz de cristalizar» (Sijé I935: 716). En La decadencia de la flauta y el reinado de los fantasmas, libro póstumo que Miguel Hernández, dada la amistad, tuvo que haber leído en el original, Sijé afirma, entre otras cosas, que: «Un objeto artístico es una participación cristalina de la realidad y de la persona». ¿De dónde surge esa denominación del poema como cristal y de la claridad poética como cristalinidad? El origen debe de estar en Le traité du Narcisse (Théorie du Symbole), de I89I, donde leemos, por ejemplo: «Car l'œuvre d'art est un cristal» (Gide, I958: IO). La teoría del cristal sijeniana explica el libro, desde su admiración por Góngora. Para Sijé, del mismo modo que Hernán Cortés quemó sus naves, el poeta ha quemado las claves, porque el poema gongorino es para él «perfectamente cristalino». De ahí que las octavas de Perito en lunas se publicaran sin título. No quiso Hernández ofrecer facilidades al lector, por eso no importa que Cano Ballesta diese a conocer un listado de títulos que cierta persona de Orihuela hubiera escrito al dictado del propio poeta (Cano I962: 37), entre otras cosas, porque ni siquiera coinciden con los que aparecen en la cuartilla original antes citada.

Poliedros, el título abandonado, denunciaba ya la huella del nuevo amigo. Cuando apareció Tiempo cenital, de Antonio Oliver, Sijé publicó en el Diario de Alicante (I9 de julio de i932) un artículo donde insiste en la materialización de la poesía que representa el poema relacionándola con la geometría. La poesía es «emoción que uno recuerda cuando se geometrizan los sentimientos al darles jerarquía, sentido arquitectónico, dimensiones y límites». El título Poliedros no puede ser ajeno al interés poético por la geometría. El poliedro más perfecto es el cristal de roca. Poliedros era título perfecto pero, tal vez, oscuro en exceso, y se confundiría con la estética rupturista de la vanguardia. Miguel ya demostró influencia simbolista cuando acude al tema de la mina de la poesía, con origen en Novalis, en la prosa «Mi concepto de poema (Pregunta y respuesta del lector y el poeta)», dada a conocer por Leopoldo de Luis (Hernández I96I: 342) y que la Obra Completa publica incomprensiblemente truncada en su título y su inicio (Hernández 1992 y 20IO).

Perito en lunas. Perito en cristales. Perito en poemas. Miguel Hernández se declara ya poeta pleno. Es el que sabe escribir poemas. ¿Qué mejor título para un poeta que había retornado de un Madrid donde nadie lo consideró como un poeta culto y que ha decidido hacer el aprendizaje definitivo? Perito en lunas quiere decir «perito en cristales», «perito en poemas», «el que sabe escribir poemas». Entenderá Hernández, para su segundo viaje a Madrid, que ya se ha aproximado a la altura de los escritores burgueses, poseedores 
de una herencia cultural cosmopolita. Pero Perito en lunas resulta ser un libro exhibicionista y ya fuera del juego estético cuando se publica.

Gerardo Diego insiste en que el gongorismo dura en la poesía española del siglo XX cinco años justos, de 1927 a 1932 (Diego 2003: passim). En 1933 Perito en lunas se salía ya del tiempo. Es verdad, como escribe Diego, que «la lección de don Luis [de Góngora] es lección de maestría, de moral poética más que de poética pura» (Diego 2003: 108). El mismo año 1933 José María Morón publicó un libro donde, desde el gongorismo, buscó superar esa estética incorporando las preocupaciones y los temas proletarios. Minero de estrellas está, desde el punto de vista estético e ideológico, un paso por delante de Perito en lunas, aunque sea poco citado (Urrutia 1986: 48-5I).

En los años posteriores fue decantando Hernández su poética. Abandonó el neogongorismo, se acercó más a expresiones líricas de tono y lenguaje místico, llegó al soneto en fórmula, primero renacentista, luego quevedesca, hasta obtener el primero de sus libros mayores, El rayo que no cesa. A esa depuración lírica le seguirían una depuración religiosa y otra ideológica, de la mano de sus amigos Aleixandre, Neruda y González Tuñón. Como le ocurrió a la misma poesía española, su evolución se vio a la vez cortada y acelerada por la guerra civil en 1936, que movió a urgencias imprevistas. Su poesía de combate se reunió mayoritariamente en el libro Viento del pueblo. Otros poetas del tiempo se vieron arrastrados a escribir poemas combatientes y a reunirlos, pero el libro de Miguel Hernández destacó inmediatamente entre todos.

César Falcón, conocido militante comunista peruano, amigo de José Carlos Mariátegui, periodista, dramaturgo, novelista y político, publicó un artículo en 1957, en la revista mexicana Estaciones, bajo el título «Poesía revolucionaria». La argumentación es sumamente discutible, pero conviene resaltar sus opiniones sobre la poesía escrita durante la guerra civil española, porque están hechas desde la más estricta or todoxia comunista. Para Falcón, aquella poesía considerada revolucionaria «tenía un aliento tan fatigado, tan inseguro, que correspondía exactamente al perseverante derrotismo de los grupos políticos que al mismo tiempo estaban liquidándose, [porque] el mismo impulso que desbarataba las endebles estructuras políticas, hacía polvo las falsas estructuras poéticas» (Falcón 1957: 136 y 135). El juicio se apoya en un sentido de la historia poética que puede resumirse en estas líneas del artículo: «A medida que el pueblo va perdiendo sus libertades bajo el dominio creciente del feudalismo, el verso popular va perdiendo también la suya, sometido igualmente a los rígidos cartabones de la preceptiva» (Falcón 1957: II5). Si la referencia al feudalismo ya nos pone tras la línea de los ensayos de Mariátegui, la crisis de la teoría poética la quiere evidenciar con esta pregunta: «iNo es sobremanera revelador que revolucionarios tan firmes como Miguel Hernández y Pedro Garfias prefirieran batirse como 
soldados que luchar como poetas?». Y en nota al pie hace un comentario que rompe los esquemas que la crítica de la poesía española utiliza: «No tomo en cuenta las poesías de guerra de estos dos poetas, como las contenidas en ese deleznable Viento del pueblo, de Miguel Hernández -deleznable desde el título-, porque ninguna de ellas alcanza, en realidad, el valor de aquel momento revolucionario». Sus poemas carecerían de otro valor que el de ocupar los ocios del poeta entre los combates. Solo destaca Falcón a cuatro poetas en la guerra: Alberti, Neruda, Vallejo y León Felipe; curiosamente, ninguno de los cuatro fue combatiente.

Si El rayo que no cesa tuvo una aceptable acogida entre los intelectuales, no fue así en el caso de Viento del pueblo. La revista Hora de España, por ejemplo, solo se ocupó de él en 1938, con un artículo muy crítico de Ramón Gaya. Este opinaba que su fuerza radicaba en el verso: «Cuando se da lo auténticamente poético, se da un poco por añadidura y con posterioridad al verso mismo, o sea, que es el verso quien le proporciona, quien termina por traerle a Miguel Hernández la poesía, y no la poesía quien dicta su verso». Porque «si siempre sus versos son versos [...], en cambio, no todos esos versos que son versos siempre, son siempre poesía». Lo considera un poeta de «desmedida facilidad», lo que provoca que por Viento del pueblo circule «un vigor que no siempre encuentra empleo apropiado y se extravía, se pierde entonces como una fuerza inútil». Concluye: «Es un libro desigual y sin medida», que cae en el «mal gusto», en la fealdad (Gaya I938: I43, I44 y I46). Este juicio, que no debió ser caso aislado, aunque sí público, rompía con los elogios dedicados al libro por su aliento vital, por testimoniar y alentar una lucha heroica.

El juicio de Ramón Gaya lo atribuí a enfrentamiento personal y, cuando leí por vez primera el artículo de César Falcón, no le di importancia. Ahora, al volver a las páginas de la revista Estaciones, creo que el texto de Falcón es muy significativo y justifica una nueva lectura de Viento del pueblo. Si tenemos en cuenta la ortodoxia comunista, y más allá del mero juicio poético, estamos ante lo que el partido realmente pensaba de la poesía de guerra, aunque no lo declarase por táctica política. Además, es una actitud coherente con los revolucionarios de primera hora, tal y como se aprecia en los ensayos de Lenin.

En un artículo sobre la validez política, de la revista Svoboda, en I9oI, Lenin denuncia que algunos escritores buscan elaborar un estilo apropiado para la lectura obrera y no logran más que populismo. Estos serían los escritores vulgares que presuponen «un lector que no piensa» y por eso le dan ya preparadas todas las conclusiones. Frente a ellos prefiere al escritor popular, que confía en un lector que posee el «serio propósito de trabajar con la cabeza» y por eso lo ayuda con su obra (Lenin 1974: I7-I8). Podemos suponer que Falcón consideraba Viento del pueblo poesía populista de un escritor vulgar. En unas observaciones para el Congreso de Proletkult, de 1920, Lenin 
advierte que el arte debe estar impregnado del espíritu de la lucha de clases que lleva a cabo el proletariado, porque busca «el derrocamiento de la burguesía, la supresión de las clases y la abolición de toda explotación del hombre por el hombre» (Lenin I974: I85). Años más tarde, Adolfo Sánchez Vázquez desarrollaría esta posición:

A veces, se piensa [...] que se puede [cultivar] un arte popular, pero entendido éste no propiamente como un arte para el pueblo sino como un arte acerca del pueblo o populista. Se cree, entonces, que basta convertir al pueblo en objeto de la representación artística y teñir los medios expresivos de un supuesto color «popular» [...] para que se tenga un arte verdaderamente popular (Sánchez Vázquez 1967: 263).

Rosa Chacel hizo en enero de I937, en el primer número de la revista Hora de España, una desacreditación del romance, tan habitual en los poemas de guerra, que no pudo pasarle desapercibida a Hernández. En un ensayo algo confuso concluye que no puede ser que «el pueblo que ve volar sobre su cabeza las máquinas forjadas por sus manos, que sabe la cifra de las revoluciones de su hélice, y sabe cómo procede en su trayectoria el proyectil que le combate; el pueblo que conoce este admirable artificio de la técnica en todo el lujo de su retórica», no puede expresarse en el balbuceo poético de la poesía primitiva (Chacel 1937: 19). Leopoldo de Luis, en «El uso del romance en la poesía de guerra de Miguel Hernández», observa que, después de Viento del pueblo, el poeta solo dio a conocer nueve romances: cuatro no recogidos en libro, dos en El hombre acecha y tres en el Cancionero y Romancero de ausencias. Opina de Luis que, aunque no se le puede encuadrar entre los poetas que rechazaron el género, percibió ese distanciamiento y buscó otro modo de reafirmarse «en un acento entrañado en lo popular» (De Luis I994: 4I).

El mismo mes de enero de 1937 en que iniciara su camino la revista Hora de España, el día 2, Miguel Hernández publicó en la revista Ayuda el poema «Las desiertas abarcas», recogido por Juan Luis Guereña (Hernández I974: I45). Recuerda en su inicio la festividad en la que los niños españoles ponen, la noche del 5 de enero, los zapatos para recoger a la mañana siguiente los regalos que, según la tradición, habrían traído los Reyes Magos. El niño Hernández dejó su calzado huertano, las abarcas, que califica socialmente: «cabrero». Miguel vuelve a retomar su personaje de pastor: «Por el cinco de enero, / cada enero ponía / mi calzado cabrero / a la ventana fría». No me detengo en los efectos de repetición ni en el doble sentido de «fría», temperatura e impasibilidad. Al día siguiente, rompiendo toda esperanza, el niño no halla juguete alguno: «Y encontraba los días / que derriban las puertas, / mis abarcas vacías, / mis abarcas desiertas».

Recordamos «El niño yuntero», de Viento del pueblo. Pero este poema está escrito en tercera persona y solo a partir de la estrofa decimoprimera se 
manifiesta el yo del sujeto lírico: «Me duele este niño hambriento», «Le veo arar los rastrojos / y devorar un mendrugo», "Me da su arado en el pecho» (Hernández 20I7: 407). En «Las abarcas desiertas» la implicación del sujeto es total; si fuese una narración aplicaríamos aquel término que inventara Serge Doubrovsky: «Autofiction, d'avoir confié le langage d'une aventure à l'aventure du langage» (Doubrovsky 200I: IO), porque es el lenguaje, y no su estricta referencia, el que da significación y nos abre el sentido.

El poeta-niño no era sino uno más en la clase menesterosa y olvidada: «Nunca tuve zapatos, / ni trajes, ni palabras: / siempre tuve regatos, / siempre penas y cabras. // Me vistió la pobreza, / me lamió el cuerpo el río / y del pie a la cabeza / pasto fui del rocío». La vida se relaciona con una naturaleza que no abriga, sino que mantiene a la intemperie. No tener juguetes el 6 de enero se corresponde con no tener casa. Ese día se convierte en fecha simbólica que enfrenta cada año la sociedad consigo misma, ya que, si «Por el cinco de enero, / para el seis, yo quería / que fuera en mundo entero / una juguetería», a la mañana se muestra la negación de cualquier felicidad: «Y al andar la alborada / removiendo las huertas, / mis abarcas sin nada, / mis abarcas desiertas».

La sociedad, el poder gobernante, rey coronado o gente de botas, nunca hizo nada por el cabrero, por los trabajadores: «Ningún rey coronado / tuvo pie, tuvo gana / para ver el calzado / de mi pobre ventana. // Toda gente de trono, toda gente de botas / se rio con encono / de mis abarcas rotas». Ante ese abandono, el poeta confiesa su dolor histórico: «Rabié de llanto, hasta / cubrir de sal mi piel, / por un mundo de pasta / y unos hombres de miel». Y se cierra el poema recogiendo la conciencia del ser social: «Por el cinco de enero / de la majada mía / mi calzado cabrero / a la escarcha salía. // Y hacia el seis, mis moradas / hallaban en sus puertas / mis abarcas heladas, / mis abarcas desiertas».

Es, sin duda, un poema político en el que Miguel Hernández se manifiesta claramente como proletario. Entiende que no puede ya defender los sistemas de gobierno que conoce. Se ha integrado en el partido comunista (en el que no estaba en septiembre de 1936) y posee todas las experiencias del combate. Resueltas meses antes su crisis religiosa (poema «Sonreídme») y su primera duda social, había comprendido que una revolución resultaba imprescindible (poema «Alba de hachas»), y esta se resume y resuelve en la lucha de clases. Naturalmente, el poema no es un discurso político y la simbolización se impone y lo organiza. Ha opuesto la gente de trono a la gente de botas. El primer término del paralelismo expresa la monarquía. Para comprender que el segundo significa el régimen republicano, recordemos que el presidente de la Segunda República española, desde I93I a abril de 1936, fue Niceto Alcalá Zamora, que gustaba de llevar botines y, por ello, fue 
apodado «el botas». Lo que podía permanecer como broma se ha convertido en símbolo.

Suele atribuirse a Lenin la brillante afirmación de que la ética es la estética del futuro. La repetía en los años sesenta del pasado siglo el cineasta francés Jean-Luc Godard, y parece que fue invento suyo tanto la frase como la atribución. Resolvía Lenin/Godard la dicotomía ético-estética que atravesaba como una bala explosiva las discusiones artísticas desde la Primera Guerra Mundial, que en España se había marcado en la relación dialéctica entre dos libros, La deshumanización del arte (1925), de José Ortega y Gasset, y El nuevo romanticismo (1930), de José Díaz Fernández (Urrutia 2006 y 2010).

Miguel Hernández personifica la ética como estética a partir de «Las desiertas abarcas», como muestra El hombre acecha; de forma muy abrupta en el poema «Los hombres viejos», donde acusa a otros intelectuales de ser: «Trapos, calcomanías, defunciones, objetos, / muladares de todo, tinajas, oquedades, / lápidas, catafalcos, legajos, mamotretos, / inscripciones, sudarios, menudencias, ruindades». Estos hombres no son simplemente escondidos y tramposos, como aquellos que dieron lugar al poema «Los cobardes», de Viento del pueblo, son gente sin moral y, por eso, el poeta usa de su palabra y afirma que «con un soplo sólo de mi caliente aliento / con este solo soplo dicté vuestra agonía» (Hernández 20I7: 407-409 y 467-471).

Podemos ejemplificar el comportamiento ético frente al estético con el distinto tratamiento que Alberti, Lorca o Pemán ofrecen del neopopularismo, frente al que concibe desde 1938 Hernández, no con el sentido de contemplación burguesa, sino a través de la experiencia del cancionero popular murciano que él vivió y del que toman su estructura muchas de las piezas del Cancionero de ausencias. Una estética para un presente que exigía una nueva ética, y una posición política clarificada y disiente que obligaría a un análisis ya fuera de nuestros límites.

\section{Bibliografía}

Balcells, José María, Proyección y contraproyecto en la poesía española contemporánea, Palma, Universidad de les Illes Balears, I99I.

-. Sujetado rayo. Estudios sobre Miguel Hernández, Madrid, Devenir, 2009.

Buero Vallejo, Antonio, «Un poema y un recuerdo», Ínsula, I68, I96o, s/p.

Cano Ballesta, Juan, La poesía de Miguel Hernández, Madrid, Gredos, 1962.

Chacel, Rosa, «Cultura y pueblo», en Hora de España, I, Valencia, 1937, pp. I3-22.

De Luis, Leopoldo, Aproximaciones a la obra de Miguel Hernández, Madrid, Libertarias/Prodhufi, I994.

Diego, Gerardo, La estela de Góngora, Santander, Universidad de Cantabria/ Fundación Gerardo Diego, 2003. 
Doubrovsky, Serge, Fils, París, Gallimard-folio, 200 .

Falcón, César, «Poesía revolucionaria. Situación de Rubén Darío y sus herederos», Estaciones. Revista literaria de México, II, 6, verano de I957, pp. II5-I37.

García Lorca, Federico, Epistolario completo, eds. Andrew A. Anderson y Christopher Maurer), Madrid, Cátedra, 1997.

Gaya, Ramón: «Divagaciones en torno a un poeta: Miguel Hernández», en Hora de España, I7, Barcelona, I938, pp. I43-I5I.

Geist, Anthony Leo, La poética de la generación del 27 y las revistas literarias: de la vanguardia al compromiso (I9I8-I936), Madrid, Guadarrama, I980.

Gide, André, Romans. Récits et soties. Euvres lyriques, Paris, Gallimard (La Pléiade), 1958.

Goffman, Erving, La presentación de la persona en la vida cotidiana, Buenos Aires, Amorrortu, 200I.

Hernández, Miguel, Obra escogida (edición de Arturo del Hoyo), Madrid, Aguilar, 1952.

—. «Dos páginas inéditas. Nota de L[eopoldo] de L[uis]», en Papeles de Son Armadans, LXIX, diciembre de I96I, pp. 339 y ss.

-. Poesía, ed. Jacinto Luis Guereña, Madrid, Narcea, I974.

—. Epistolario, ed. Agustín Sánchez Vidal, Madrid, Alianza Editorial, 1986.

-. Obra Completa, eds. Agustín Sánchez Vidal, José Carlos Rovira y Carmen Alemany, Madrid, Espasa-Calpe, 1992.

-. Obra Completa, introd. Agustín Sánchez Vidal, Madrid, Espasa-Calpe, 2010.

- Obra poética completa, ed. Leopoldo de Luis y Jorge Urrutia, Madrid, Alianza Editorial, 2017 (I2 ${ }^{\text {a }}$ edición revisada).

Lenin, Vladimir Ilich, La literatura y el arte, La Habana, Instituto Cubano del Libro, I974.

López-Baralt, Mercedes, «Tradición y vanguardia: Las fuentes múltiples de Miguel Hernández», en AA.VV., Miguel Hernández. La sombra vencida I9I0-20Io, Madrid, Ministerio de Cultura, 20Iо, pp. 78-89.

Machado, Antonio, Juan de Mairena, Madrid, Espasa-Calpe, I936.

Muñoz Garrigós, José, Vida y obra de Ramón Sijé, Murcia, Universidad de Murcia, I987.

Sánchez Vázquez, Adolfo, Las ideas estéticas de Marx (Ensayos de estética marxista), México, Era, 1967.

Santonja, Gonzalo, «Miguel Hernández en Madrid», en Liberación, Madrid, domingo 30 de diciembre de 1984 .

Sijé, Ramón, «La ausencia del alma y del objeto (Sonrisa y cólera en la poesía de Rafael Alberti)», El gallo crisis, 5-6, I935. Recogido en Muñoz Garrigós 1987 . 
- La decadencia de la flauta y el reinado de los fantasmas. Ensayo sobre el romanticismo histórico en España (I83o-Bécquer), Alicante, Instituto de Estudios Alicantinos, 1973.

Urrutia, Jorge, «Poesía proletaria y poesía burguesa: definición y prácticas», en Literatura popular y proletaria, ed. Jorge Urrutia, Universidad de Sevilla, 1986, pp. 27-52.

—. «Leer a Miguel Hernández (Perito en lunas y el modelo comunicativo hernandiano)», en Presente y futuro de Miguel Hernández. Actas del II Congreso Internacional, Orihuela, Fundación Cultural Miguel Hernández, 2004, pp. 95-I06.

—. «Vitalidad de la deshumanización del arte», Revista de Occidente, 300, mayo, 2006, pp. 5-22.

—. «En torno a José Díaz Fernández y El Nuevo Romanticismo», en Pensamiento literario español del siglo $\mathrm{XX}, 4$, eds. Túa Blesa y otros, Zaragoza, Universidad de Zaragoza (col. Tropelías), 2010, pp. I83-192.

—. «Miguel Hernández, el hacedor de poemas», Ínsula, 763-764, julio-agosto, 2020, pp. I-6. 
